\title{
Preservation and Conservation Strategies of Historical Textiles in Excavation: A Case Study of Egyptian Excavation
}

\author{
Harby E Ahmed* \\ Department of Conservation, Cairo University, Egypt \\ *Corresponding author: Harby E Ahmed, Department of Conservation, Faculty of Archeology, Cairo University, Egypt \\ submission: 眥June 18, 2018; Published: 㘹 July 11, 2018
}

\begin{abstract}
The Tuna el-Gebel excavation is a model of excavation in Egypt. Historical textiles were found in the excavation in poor conservation state and risked further deterioration if left untreat.A close examination of the textile was followed by various Nan- distractive analyses in order to develop a plan of conservation treatment. This research shows the practical strategies, which have to be followed in maintaining, and conserving textiles. The effects of cleaning materials on the natural dyes were tested. Dry cleaning was used to remove resistance stain and dirt. The process of maintenance and restoration has been recorded step by step -beginning from the historical record of the textile to the cleaning process with its different kinds. Add to this, the processes of fixing pieces on new holder as a preparation for displaying or storage in museum.
\end{abstract}

Keywords: Stain;Cleaning;Solvents; SEM;Natural dyes;Storage;Excavation

\section{Introduction}

The excavation of Tuna el-Gebel was a scientific joint venture between the Institute of Egyptology of the University of Munich, Germany and the University of Cairo, Egypt. The ibis burial place at Tuna el-Gebel, located at west of the ancient city of Thermopolis Magna, has been the first, and for a long period, the only ibis and baboon animal cemetery during the reign of Pharaoh Pasmetkhos (664-619 BC). The number of ibises deposited in the extensive subterranean galleries network clearly exceeds one million individuals in total. In addition, to the bundles and mummies of Sacred and Glossy. Ibises which constitute most part of the collection $(>80 \%)$, at least 115 other vertebrate taxa could be found in the galleries, comprising domestic (cattle, sheep, dogs and cats). Wild mammals (such as shrews, monkeys, ichneumons, wild cats, and gazelles), reptiles (crocodiles and snakes) and fishes, as well

\section{Describation of the object}
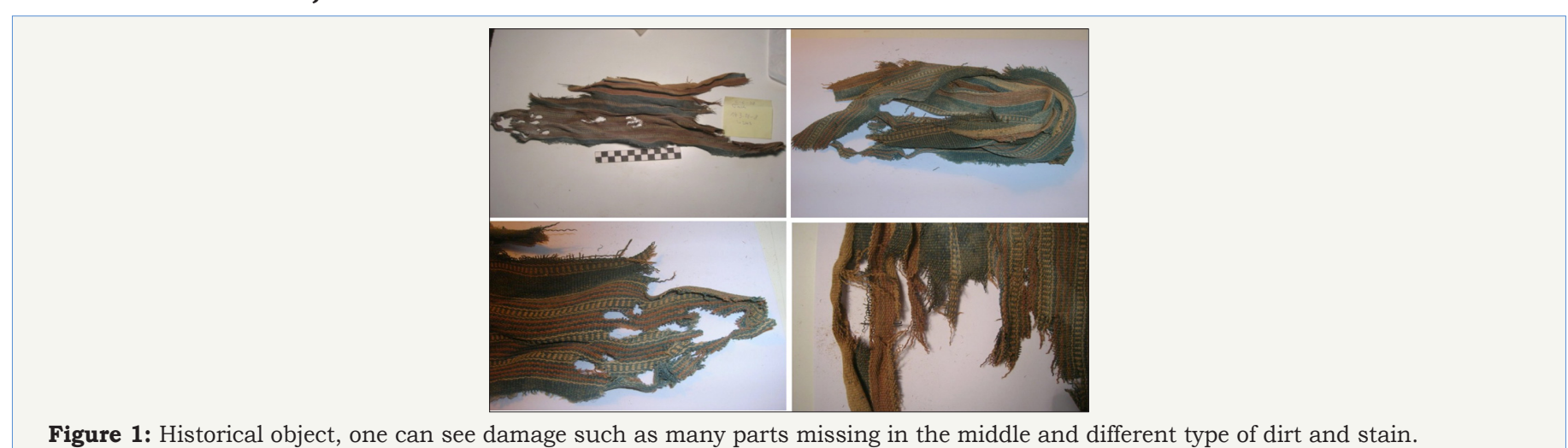

Figure 1: Historical object, one can see damage such as many parts missing in the middle and different type of dirt and stain.

as a huge variety of birds (such as herons, storks, geese, ducks, birds of prey, and owls). The archaeological zone of Tuna el-Gebel is situated in a flat desert landscape at west of the cultivated Nile valley, $5 \mathrm{~km}$ to the south of the modern village, opposite to a wide desert valley [1].

Textiles are sensitive materials since they are very prone to damage when exposed to light, heat, humidity, pollution and microorganisms. They are extremely vulnerable to decay when stored or displayed in inappropriate environmental conditions. The main purpose of this conservation intervention is to improve the properties of the textile objects, enhancing their long term stability by slowing down the rate of further deterioration. Conservation processes comprised cleaning disinfection, consolidation, mounting and storage [2]. 
The historical object is textile with horizontal threads colored with blue, brown and dark beige was unearthed (Figure 1). The object (registry number T.G 4245) belongs to the Ptolemaic era and was found in the Tuna el-Gebel excavations (Gallery D-D-2) in February 2001. The historical textile is severely damaged and there are many parts missing in the middle. Furthermore, it is contain different type of dirt and stain.

\section{Examination of metal threads}

Visual examination of object was done in order to identify the type-missing parts and weak parts, and all the deterioration aspects were recorded by photograph. One can see, the object is highly free dusted. Optical microscopy is used for preliminary examination of morphology of the threads. Scanning electron microscopy with energy-dispersive X-ray microanalysis (SEM/EDS) is the most frequently used analytical technique for determination of the composition. The SEM images provide a characteristic surface morphology and are useful for judging the surface structure of the investigated sample, its fibers quality as well as its damage aspects. A combination of transmitted light microscope and SEM was used to reveal diagnostic features of the fibers necessary for their identification. The morphology of the surface of the fibers was investigated using (Joel- Scanning Electron Microscope) (Figure 2).

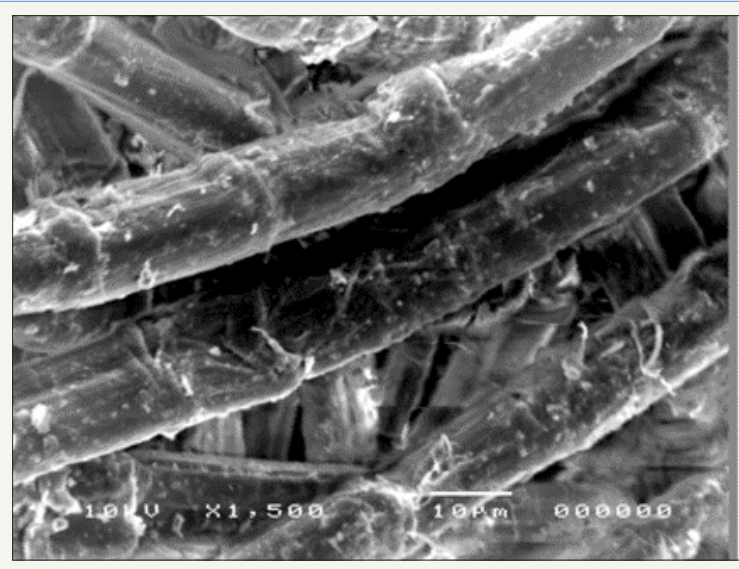

Figure 2: SEM of historical object, one can see the fiber is linen.

\section{Mechanical cleaning}

The aim of conservation cleaning is to remove harmful soils, which may be disfiguring or cause physical or chemical damage to a textile. Selection of the appropriate cleaning method depends on the nature of the soil present, and on the materials, structure, and condition of the textile. Thorough testing should always be carried out first to determine the response of the textile to cleaning and to identify the most suitable method [2]. Various types of fine brushes are used to remove free dust, dirt and fragile upper layers from corrosion. Aerobic aspiration of dust was done by using a vacuum cleaner $[3,4]$.

\section{Testing the stability of dyes}

The important step was to test the stability of the natural dyes to wet cleaning by immersing a piece of cotton wrapped round a wooden stick into the cleaning solutions and placing it in contact with the colorful parts of the ribbons. It was found that all the dyes were stable and did not bleed with the wet cleaning solution [5].

\section{The wet cleaning procedure}

The fabric webbing primary support was done in order to keep the fragile parts of the historic object. Then, a temporary Washing bath was built by using four wooden tires, then lining the bath by polyethylene. This cleaning procedure used water with other detergent agents, to assist the cleaning process. The ratio was one part a neutral synthetic anionic detergent Orvus WA Paste (Sodium Lauryl Sulfate) to 100 parts of distilled water. The water was agitated to allow it to penetrate between the fibers to release

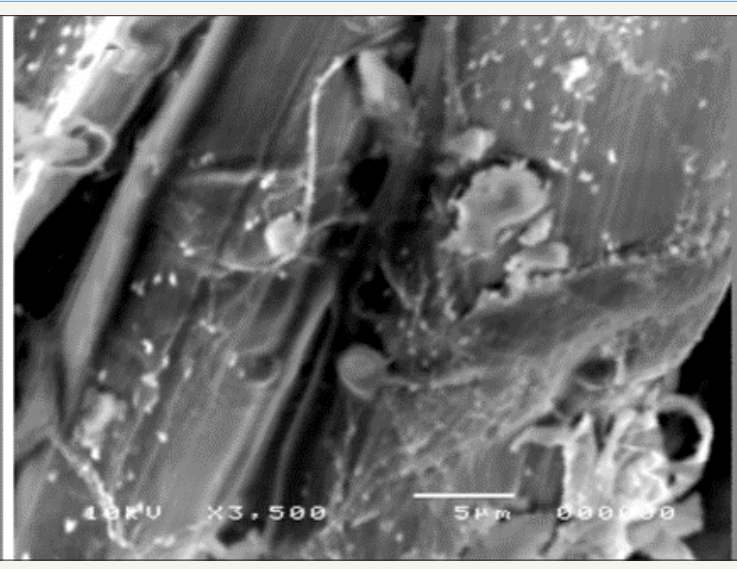

the dirt particles, for $15 \mathrm{mins}$. The bath temperature was $30{ }^{\circ} \mathrm{C}$. Then a second cleaning bath with distilled water only was applied for $10 \mathrm{mins}$ again with water agitation, and then a third bath with distilled water only, for $10 \mathrm{mins}$. The wet cleaning reduced the soiling, relaxed the fibers, removed the creasing and brightened the colors $[6,7]$.

\section{Dry cleaning}

The object contains different type of stain and dirt. The researcher try to test different cleaning methods. The mechanical and wetting cleaning processes help remove mud's dirt but these methods are ineffective to remove some type of dirt. Only dry cleaning by using ethanol is very effective to remove the stain that difficult to remove by wet cleaning. In general, dry cleaning solvents such as aliphatic hydrocarbons, aromatic hydrocarbons, alcohols, ketones, esters, ethers, chlorinated solvents, nitrogen compounds, organic bases and sulphur compounds will attack greasy, oily soils and waxes at room temperatures. Thus, there has been an attempt for using ethanol in localized way for the soiling parts by using smooth brushes to help remove spots after 15 minutes. Two baths of ethanol were used for 15 minutes with smooth brushes to remove soiling. The result is very effective and we can note the pictures before and after use which show the extent of the ethanol's efficiency. A bath without soap for five minutes to remove any undesired remnants and for equalizing the effect of ethanol on fibers was done. Furthermore, the white oil paint was removed from the metallic threads by Ethanol [8-10] (Figure 3). 


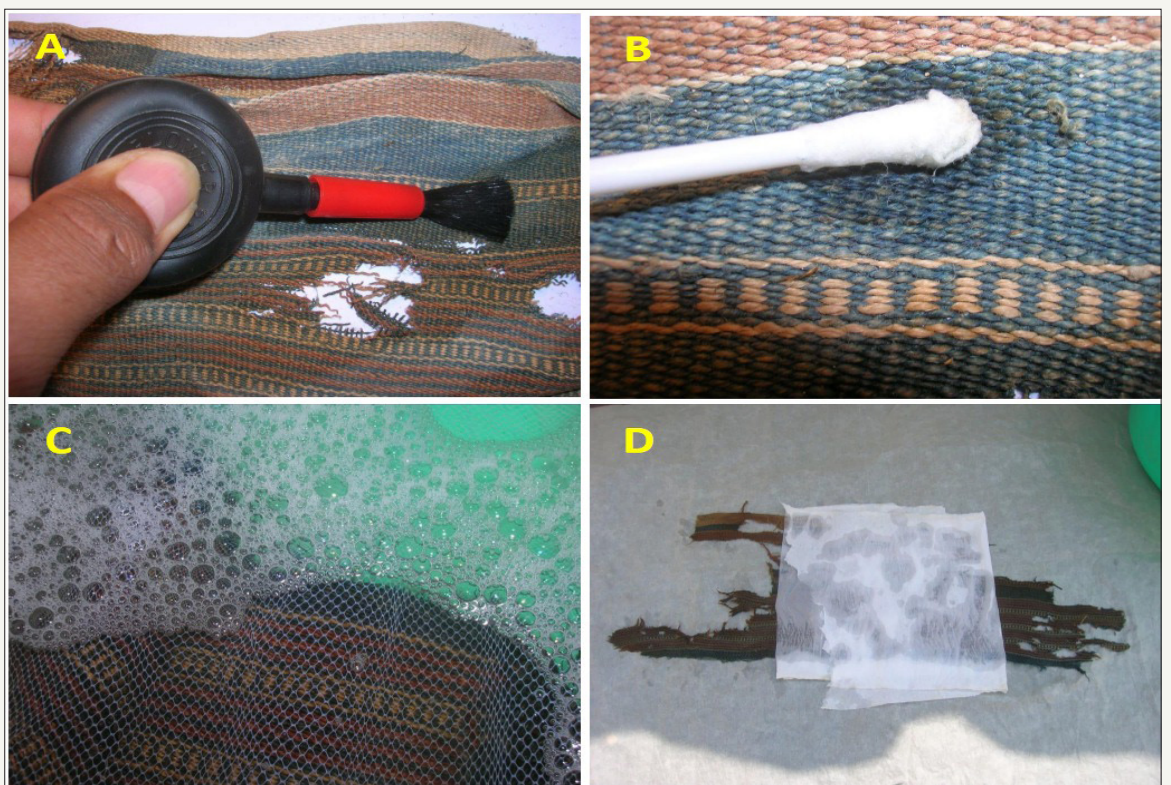

Figure 3: Mechanical cleaning of historical object (A), Testing the stability of dyes (B), Wet cleaning (C), Drying process (D).

\section{Removing the water from the textiles}

Two different methods were used in order to removing the water from the object after cleaning. The second method is using the Japanese paper (Acid free paper) is laid directly onto the surface of the textile and again pressed carefully with the hands. Always keep in mind that the textile at this stage is still soft due to its wet state and can easily be damaged during this handling, so a great deal of care must be exercised. Consequently, the object was left uncovered to complete drying at ambient conditions. In air-drying, the process can be shifted towards evaporation in several ways: by ensuring that the wet textile is setted in a place (i.e. workroom) that is sufficiently large in comparison to the size and surface area of the drying textile. Furthermore, by ensuring that water vapor is removed as soon as it is formed e.g. with the help of dehumidifiers and/or effective ventilation $[2,10,11]$.

\section{The final support}

In order to prepare the textile for storage and display, it is necessary to provide the fabric with a new support to increase its strength. For this, a carpenter from a nearby village to the location of excavations prepared a wooden support. The wooden support was later coated with Paraloid B72 (10\%in acetone) to isolate the wood from the environmental conditions, minimizing thus the movements of the wooden frame. The wooden support was covered by soften textile. Later, a new undyed linen support was prepared and washed to remove any chemical residues from the sizing and finishes, and to prevent shrinkage at a later time due to the humidity changes. After washing and drying, the linen was ironed to remove creases and it was then attached to the wooden support $[12,13]$ (Figure 4).
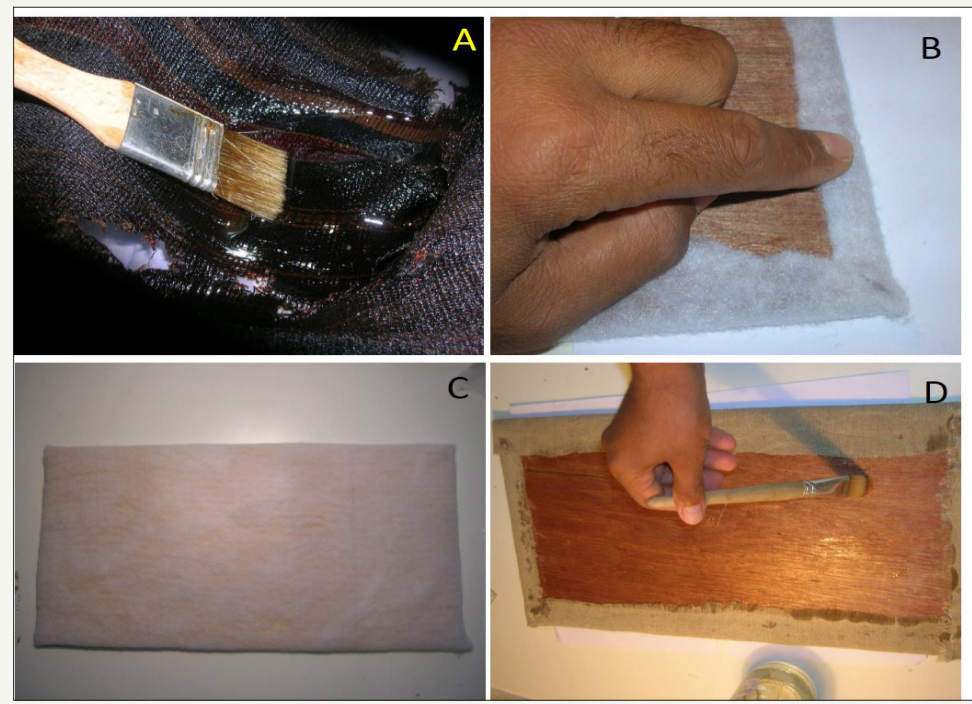

Figure 4: Dry-cleaning of historical object (A), Wooden support was covered by soften textile (B \& C), The linen support was attached to the wooden support (D). 


\section{Mounting}

Once the new fabric support was prepared, the textile object was placed carefully over the fabric. In mounting, it is important to choose the right materials such as needles and threads to provide the maximum visual satisfaction and to ensure of the future stability without the risk of adverse effects. In this project, a very fine undyed silk thread was used. In the beginning, the object was fixed in the support with wide stitches to preserve its place. Later on, two types of stitches were used: the first type, an overcast stitch, was used to support the edges of the object; and the second type, a running stitch, was used to support the internal areas adjacent to primary stitches and damaged areas. These stitches ensured that the mounted textile was not strained, although they were tight enough to prevent movements or abrasion on the mounting. The mounting is the last stage of the interventions, after which the object becomes ready for either storing or display $[2,14,15]$ (Figure $5)$.

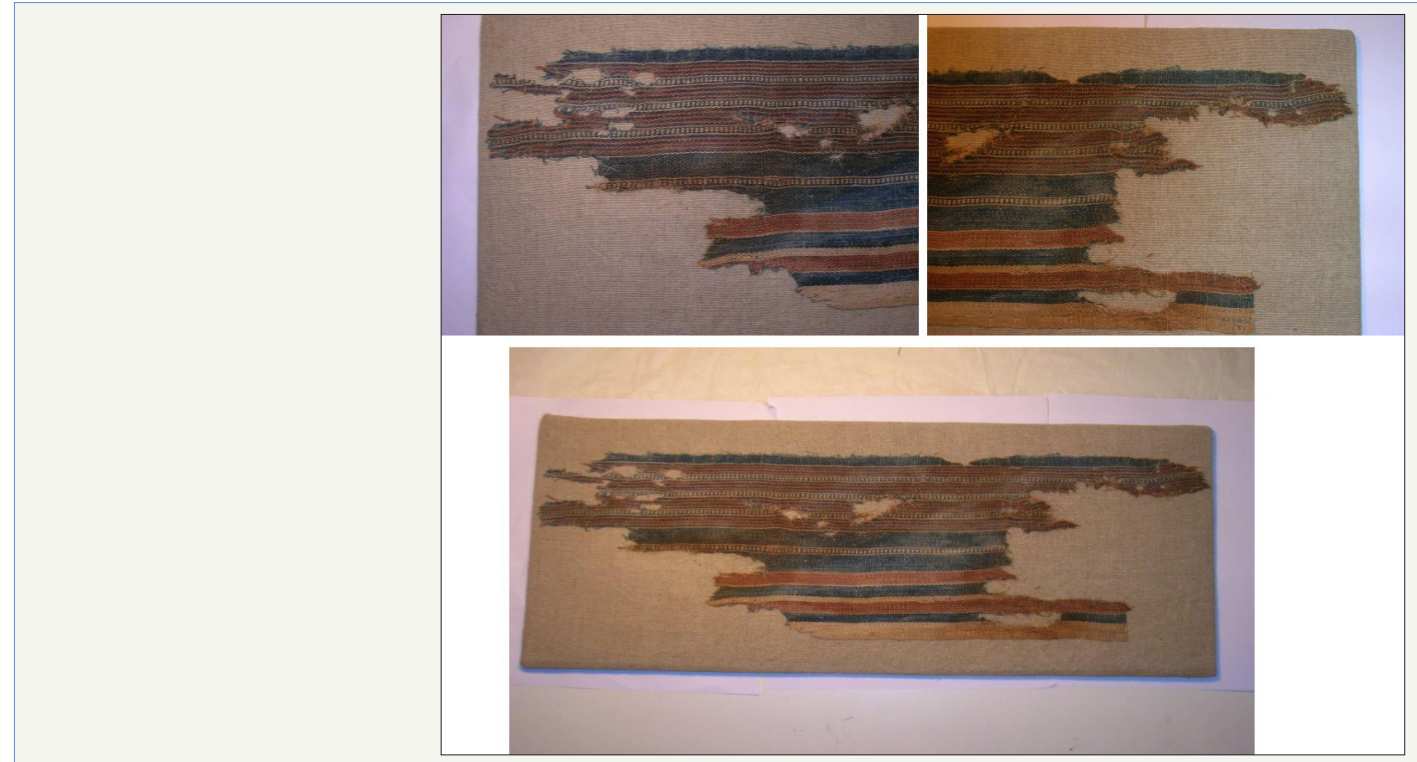

Figure 5: Historical object that attached to the wooden support b stitching, the object now is ready to display or storage in the museum.

\section{Conclusion}

This article describe conservation strategies of a textile found in the archeological excavations in Tuna el-Gebel, Egypt. SEM images of the historical textile found that the threads are made of linen fibers. The object is containing different color and the object woven is plan $1 / 1$. The objects surface presented an intense accumulation of dust and dirt affecting its mechanical properties and the appearance of the object, giving it a dull grey and opaque tone. Cleaning process of the historical object is increasing its stability and flexibility. One can see improvement of the appearance and integrity of the object after the intervention done. After the cleaning and its mounting, the object is free from dirt, has become softer and it is aesthetically more pleasing. It is recommended that the historical object textiles should be moved from the excavation to the to the Museum storage as soon as possible after the conservation treatment.

\section{References}

1. Von den Driesch A, Kessler D (2005) Mummified, deified and buried at Hermopolis Magna the sacred birds from Tuna el-Gebel, Middle Egypt. Ägypten und Levante/Egypt and the Levant 15: 203-244.

2. Tímár-Balázsy Á, Eastop D (1998) Chemical principles of textile conservation, Routledge, UK.

3. Tímár-Balázsy Á (2000) Wet cleaning of historical textiles: surfactants and other wash bath additives. Studies in conservation 45(sup3): 46-64.
4. Ahmed HE, Ziddan YE (2011) A new approach for conservation treatment of a silk textile in Islamic Art Museum, Cairo. Journal of Cultural heritage 12(4): 412-419.

5. Landi S (1998) The textile conservator's manual, Routledge, UK.

6. Rice JW (1972) Dry cleaning versus wet cleaning for treating textile artifacts. International Institute for Conservation of Historic and Artistic Works 12(2): 50-55.

7. Aslanidou D, Tsioptsias C (2013) A novel approach for textile cleaning based on supercritical $\mathrm{CO}_{2}$ and Pickering emulsions. The Journal of Supercritical Fluids 76: 83-93.

8. Ahmed HE, Gremos SS (2010) Enzymatic removal of the oily dirt from a coptic tunic using the enzyme lipase. Journal of Textile and Apparel, Technology and Management 6(3): 1-17.

9. Ahmed HE (2014) A new approach to the conservation of metallic embroidery threads in historic textile objects from private collections. International Journal of Conservation Science 5(1): 21-34.

10. Mason TJ (2016) Ultrasonic cleaning: An historical perspective. Ultrason sonochem 29: 519-523.

11. Ahmed HE, Kolisis FN (2012) A study on using of protease for removal of animal glue adhesive in textile conservation. Journal of Applied Polymer Science 124(5): 3565-3576.

12. Greene FS (1955) The cleaning and mounting of a large wool tapestry. Studies in conservation 2(1): 1-16.

13. Pow CV (1970) The conservation of tapestries for museum display. Studies in conservation 15(2): 134-153. 
14. Ahmed HE (2011) First aid of rare ptoemaic textile in tuna el-gebel excavation, Egypt. E-Conservation journal 2: 3-12.
15. Ahmed HE (2011) Stratey for preservation of ptoemaic wrapped mummys linen in tuna el-gebel excavtion, Egypt. International Journal of Conservation Science 2(3).

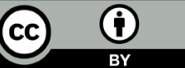

Creative Commons Attribution 4.0 International License

For possible submissions Click Here

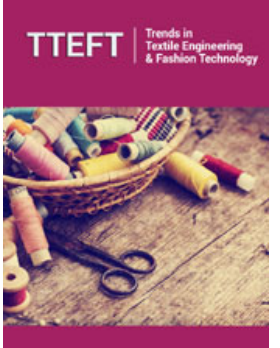

Trends in Textile Engineering \& Fashion Technology

\section{Benefits of Publishing with us}

- High-level peer review and editorial services

- Freely accessible online immediately upon publication

- Authors retain the copyright to their work

- Licensing it under a Creative Commons license

- Visibility through different online platforms 